\title{
Mononuclear Silver Complexes for Efficient Solution and Vacuum-processed OLEDs
}

Alexander S. Romanov, ${ }^{[\mathrm{a}]}$ Saul T. E. Jones, ${ }^{[\mathrm{b}]}$ Le Yang,${ }^{[\mathrm{b}]}$ Patrick J. Conaghan, ${ }^{[\mathrm{b}]}$ Dawei Di, ${ }^{[\mathrm{b}]}$ Mikko Linnolahti, ${ }^{* \mathrm{c}]}$ Dan Credgington, ${ }^{*[\mathrm{~b}]}$ and Manfred Bochmann ${ }^{*[\mathrm{a}]}$

${ }^{\text {[a] }}$ Dr. A. S. Romanov https://orcid.org/0000-0003-2617-6402, Prof. Dr. M. Bochmann https://orcid.org/0000-0001-7736-5428, School of Chemistry, University of East Anglia, Earlham Road, Norwich, NR4 7TJ, UK;

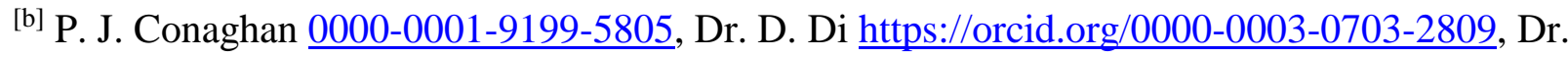

L. Yang, S. T. E. Jones https://orcid.org/0000-0001-6007-2530, Dr. D. Credgington https://orcid.org/0000-0003-4246-2118, Department of Physics, Cavendish Laboratory, Cambridge University, Cambridge CB3 OHF, UK

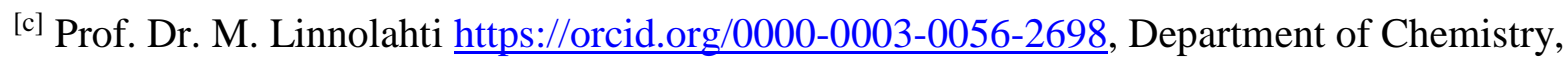
University of Eastern Finland, Joensuu Campus, FI-80101 Joensuu, Finland

Keywords: OLED, silver complex, carbene ligand; photoluminescence; electroluminescence; electrochemistry.

\section{Graphical Abstract:}

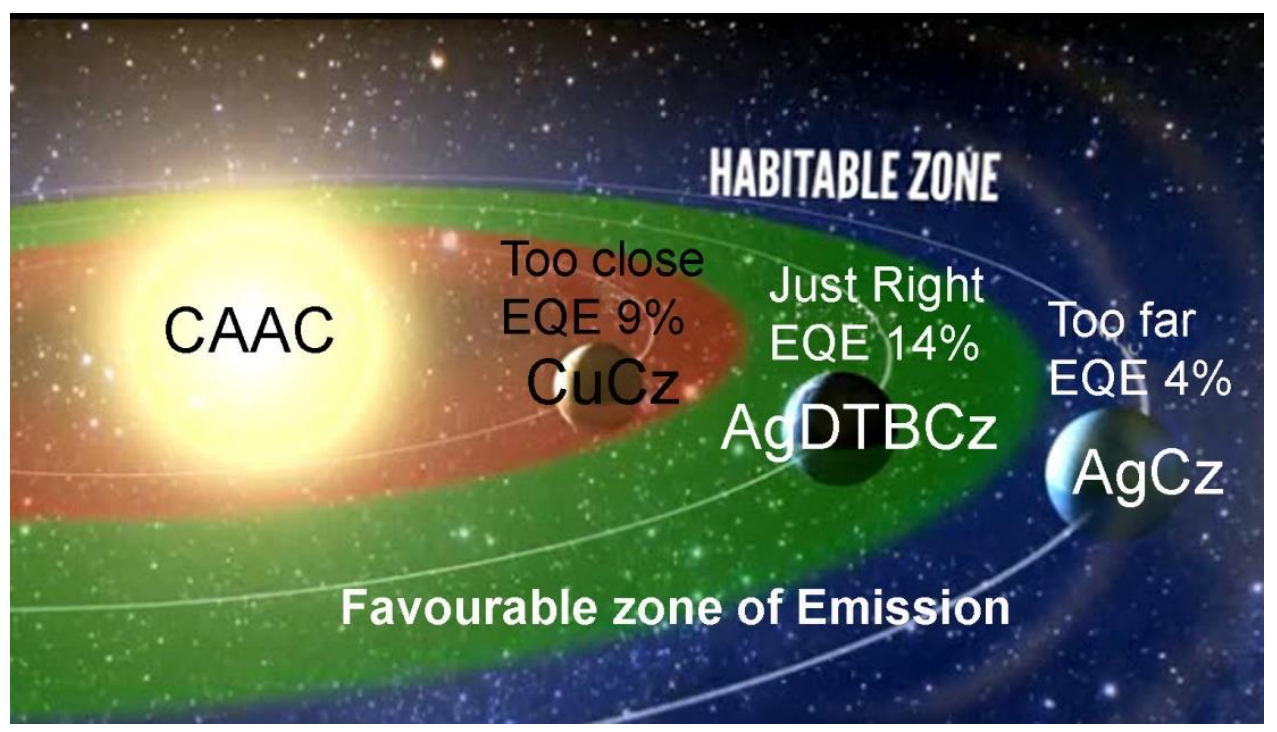




\section{ABSTRACT:}

Carbene metal amides (CMAs) are a new class of highly efficient light-emitting molecules based on a linear donor-metal-acceptor geometry. Here we report the synthesis, structure, photo- and electroluminescence of carbene silver carbazolato complexes, $\left({ }^{\mathrm{Ad}} \mathrm{L}\right) \mathrm{Ag}(\mathrm{Cz})\left[{ }^{\mathrm{Ad}} \mathrm{L}=\right.$ adamantylsubstituted cyclic (alkyl)(amino)carbene; $\mathrm{Cz}=$ carbazolate $(\mathbf{1})$ and $\left.3,6-{ }^{\mathrm{t}} \mathrm{Bu}_{2} \mathrm{Cz}(\mathbf{2})\right]$. They display green emission with photoluminescence quantum yields of up to $74 \%$. Efficient mixing of triplet and singlet excited states is observed, with sub-microsecond thermally activated radiative triplet lifetimes. These complexes provide prototype organic light-emitting diodes (OLEDs) based exclusively on silver emitters, with external quantum efficiencies of up to $14 \%$.

Coinage metal complexes are noted for their ability to emit light by phosphorescence or thermally activated delayed fluorescence (TADF) mechanisms. ${ }^{[1]}$ We have recently reported the synthesis and properties of photoemissive complexes of the type (CAAC) $\mathrm{MX}(\mathrm{M}=\mathrm{Cu}, \mathrm{Ag}, \mathrm{Au} ; \mathrm{X}=$ halide, aryloxide or amide; $\mathrm{CAAC}=$ cyclic alkyl(amino) carbene $),{ }^{[2-4]}$ with amide complexes $\left(\mathrm{X}=\mathrm{NPh}_{2}\right.$ or carbazolate) being particularly effective. ${ }^{[5]}$ In these linear compounds the metal links CAAC carbene ligands with carbazolate $(\mathrm{Cz})$ anions to give a rotationally flexible donor-metal-acceptor type structure. Using gold compounds $\left({ }^{\mathrm{Ad}} \mathrm{L}\right) \mathrm{AuCz}$, organic light-emitting diodes (OLEDs) with near- $100 \%$ internal quantum efficiencies at high brightness have been achieved. ${ }^{[5,6]}$ However, there are currently no examples of practical electroluminescence (EL) devices based on mononuclear silver. ${ }^{[7]}$ Indeed, OLED devices based on $2^{\text {nd }}$ row metals in general are remarkably rare and characterized by low efficiency. ${ }^{[8]}$ Here, we report silver complexes with sub-microsecond radiative triplet lifetimes and high performance in both solution and vacuum-deposited OLED devices.

Complexes 1 and 2 were readily obtained from $\left({ }^{\mathrm{Ad}} \mathrm{L}\right) \mathrm{AgCl}^{[3]}$ and carbazole / $\mathrm{NaO}^{\mathrm{t}} \mathrm{Bu}$ as off-white (1) or yellow (2) solids (Figure 1). The compounds are stable for long periods of time both in air and in solution in non-protic organic solvents. Unlike many silver complexes, they are not sensitive to ambient light. Thermogravimetric analysis (TGA) gives decomposition temperatures (5\% weight loss) of 264.8 (1) and $263.6{ }^{\circ} \mathrm{C}(\mathbf{2})$. The observation of the ${ }^{13} \mathrm{C}$ (carbene) NMR signal $\left(\delta_{\mathrm{C}} 263\right)$ as two sharp ${ }^{13} \mathrm{C}-{ }^{109} \mathrm{Ag}$ and ${ }^{13} \mathrm{C}-{ }^{107} \mathrm{Ag}$ coupled doublets $\left(J_{\mathrm{AgC}}=219\right.$ and 189 $\mathrm{Hz}$, respectively) confirmed that the complexes do not undergo carbene ligand exchange. ${ }^{[9]}$ 

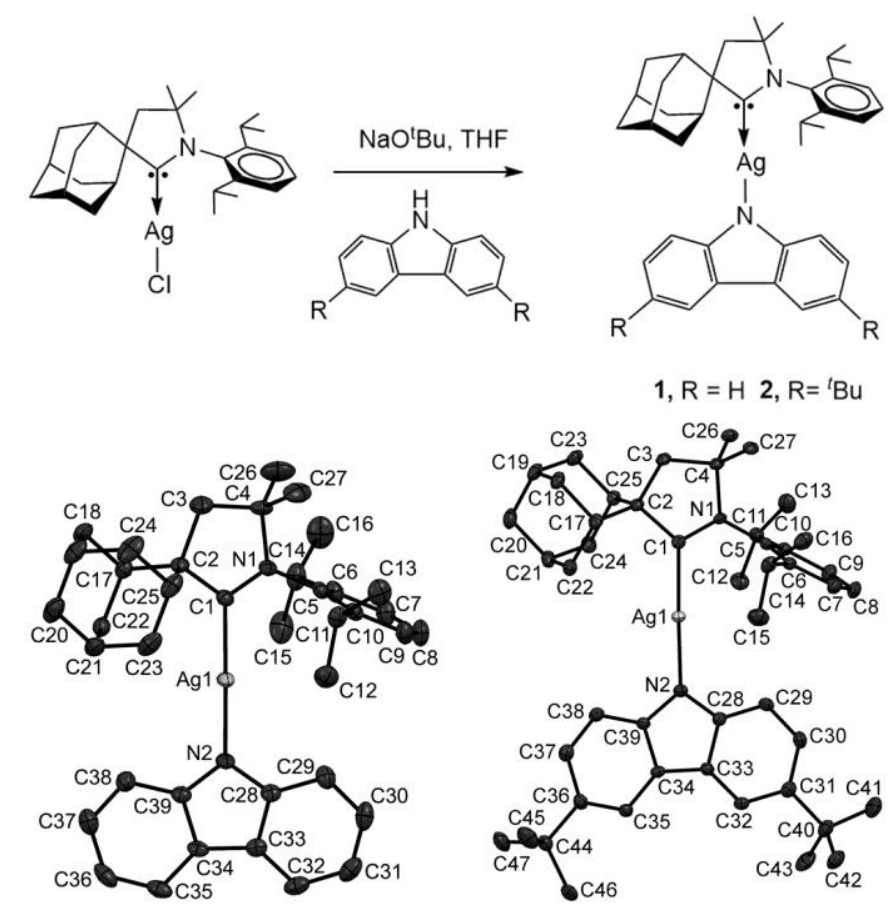

Figure 1. Synthesis and crystal structures of $\mathbf{1}$ and $\mathbf{2} \cdot \mathrm{CH}_{2} \mathrm{Cl}_{2}$. Ellipsoids are shown at $50 \%$ probability. Hydrogen atoms and $\mathrm{CH}_{2} \mathrm{Cl}_{2}$ molecule are omitted for clarity. For geometric parameters see Table 1.

Single crystal X-ray diffraction of $\mathbf{1}$ and $\mathbf{2}$ confirmed the mononuclear two-coordinate geometry and the absence of significant intermolecular contacts. The $\mathrm{C} 1(\mathrm{CAAC}) \cdots \mathrm{N} 2(\mathrm{Cz})$ distance is of prime importance since it is directly related to the HOMO-LUMO overlap, which impacts on the radiative rate and exchange energy of (carbene)metal amides; this distance is slightly longer for $\mathbf{1}(4.152 \AA)$ than for $\mathbf{2}(4.125 \AA)$.

Table 1. Comparison of bond distances $[\AA]$ and angles $\left[{ }^{\circ}\right]$ of the isostructural series $\left({ }^{\mathrm{Ad}} \mathrm{L}\right) \mathrm{M}(\mathrm{Cz})$ $(\mathrm{M}=\mathrm{Cu}, \mathrm{Ag}, \mathrm{Au})$.

\begin{tabular}{lllll}
\hline$\left.{ }^{\mathrm{Ad}} \mathrm{L}\right) \mathrm{M}(\mathrm{Cz})$ & $\mathrm{M}=\mathrm{Cu}^{a}$ & $\mathrm{M}=\mathrm{Ag}, \mathbf{1}$ & $\mathrm{M}=\mathrm{Ag}, \mathbf{2}$ & $\mathrm{M}=\mathrm{Au}^{a}$ \\
\hline $\mathrm{M} 1-\mathrm{C} 1$ & $1.884(2)$ & $2.085(2)$ & $2.073(3)$ & $1.991(3)$ \\
$\mathrm{M} 1-\mathrm{N} 2$ & $1.862(1)$ & $2.067(1)$ & $2.052(2)$ & $2.026(2)$ \\
$\mathrm{C} 1-\mathrm{N} 1$ & $1.305(2)$ & $1.294(2)$ & $1.311(3)$ & $1.299(4)$ \\
Angle C1-M1-N2 & $174.34(6)$ & $178.55(7)$ & $178.26(10)$ & $178.78(11)$ \\
Torsion angle N1-C1-N2-C28 & 7.8 & $19.9(4)$ & $16.2(3)$ & 17.6
\end{tabular}

${ }^{a}$ From ref. [5]. 
Both 1 and $\mathbf{2}$ show a quasi-reversible one-electron metal-centered reduction process (THF solution, $\left[{ }^{n} \mathrm{Bu}_{4} \mathrm{~N}\right] \mathrm{PF}_{6}$ as supporting electrolyte; SI, Figures S2, S3; Table S1). The estimated LUMO energies (1: -2.86 eV; 2 : $-2.83 \mathrm{eV})$ compare well with those for the $\mathrm{Au}(-2.79 \mathrm{eV})$ and $\mathrm{Cu}$ analogues $(-2.66 \mathrm{eV})^{[5]}$ and are only marginally affected by the nature of the metal. The peak-to-peak separation $\Delta E_{p}$ is smaller for $2(124 \mathrm{mV})$ than for $\mathbf{1}(185 \mathrm{mV})$, indicating higher stability of the reduced species of $\mathbf{2}$, potentially making it a more robust emitter under electrical excitation. The HOMO levels based on the onset of the first oxidation potentials are at -5.51 and $-5.29 \mathrm{eV}$ for $\mathbf{1}$ and 2 , respectively. These values guide the identification of host materials for OLED fabrication. ${ }^{[10]}$

The electronic structure of $\mathbf{1}$ and $\mathbf{2}$ has been evaluated using density-functional theory (DFT) for the ground state and time-dependent DFT (TD-DFT) ${ }^{[11]}$ calculations for the excited states using the MN15 functional by $\operatorname{Truhlar}^{[12]}$ in combination with def2-TZVP basis set by Ahlrichs. ${ }^{[13-15]}$ The calculated $\mathrm{S}_{0}$ geometries are in good agreement with the crystal structures and the excited state energies suffer very little from the underestimation typical for TD-DFT. ${ }^{[16]}$ Excitation involves a ligand-to-ligand charge transfer (LLCT) process from the carbazole to the carbene (SI, Figure S4, Tables S3, S4). Vertical $S_{0} \rightarrow S_{1}$ excitation of $\mathbf{1}$ and $\mathbf{2}$ is dominated by the HOMO $\rightarrow$ LUMO transition (98\%). The HOMO is mostly located on the carbazole with ca. 5\% contribution from the silver atom, while the LUMO is centred on the $\mathrm{C}_{\text {carbene }} \mathrm{p}$-orbital. The small d-orbital contributions are consistent with the insensitivity of the redox potentials of these compounds to the choice of metal. Distortion of the linear geometry was observed for the optimized $\mathrm{S}_{1}$ and $\mathrm{T}_{1}$ states: compared to $\mathrm{S}_{0}$, the $\mathrm{C} 1-\mathrm{Ag}-\mathrm{N} 2$ angle is $6-8^{\circ}$ smaller, while the $\mathrm{C}-\mathrm{N}$ (CAAC) bond is elongated by $0.07-0.09 \AA$, with simultaneous shortening of $\mathrm{C} 1-\mathrm{Ag}$ and elongation of $\mathrm{N} 1-\mathrm{Ag}$ bonds. Calculations suggest that the optimized $\mathrm{S}_{1}$ structure is twisted by $41^{\circ}$ for silver complexes (compared to $66^{\circ}$ for copper and nearly $90^{\circ}$ for gold analogues at the same level of theory). The relaxed $\mathrm{S}_{1}$ energy is very weakly dependent on the dihedral angle, while $\mathrm{T}_{1}$ has a stronger angular dependency (SI, Figure S15). The calculated exchange energy $\Delta E\left(\mathrm{~S}_{1}-\mathrm{T}_{1}\right)$ for 1 and 2 at a $45^{\circ}$ twist angle is $0.08 \mathrm{eV}\left(645 \mathrm{~cm}^{-1}\right)$, while $S_{1}$ and $T_{1}$ states are approximately degenerate at full rotation.

The photophysical properties of the materials $\mathbf{1}$ and $\mathbf{2}$ were investigated using absorption and photoluminescence (PL) spectroscopy. CAAC and carbazole ligands show $\pi-\pi^{*}$ absorptions up to $360 \mathrm{~nm}$ which overlap with a broad ligand-to-ligand charge transfer LLCT 
$\left\{\pi(\right.$ carbazole $\left.) \rightarrow \pi^{*}(\mathrm{CAAC})\right\}$ band at 388 and $400 \mathrm{~nm}$ for $\mathbf{1}$ and $\mathbf{2}$ in THF (Figure 2 and SI, Figures S5, S6, Table S2). Compared to 1, the UV/vis profile of 2 in THF solution is red-shifted by $6 \mathrm{~nm}$. Molar extinction coefficients for 1 and 2 at $\mathrm{CT}_{\max }$ in THF are $\sim 1-2 \times 10^{3} \mathrm{M}^{-1} \mathrm{~cm}^{-1}$, somewhat lower than those observed for $\mathrm{Au}$ and $\mathrm{Cu}$ analogues $\left(\sim 5 \times 10^{3} \mathrm{M}^{-1} \mathrm{~cm}^{-1}\right)^{[5]}$ and consistent with reduced HOMO-LUMO overlap owing to the larger C1-N2 distance. The position of the CT absorption edge blue-shifts by $>50 \mathrm{~nm}(350 \mathrm{meV})$ with increasing solvent polarity, from benzene (dipole moment $0 \mathrm{D})$ to acetonitrile $(3.92 \mathrm{D})$, and the relative extinction coefficient of the CT transition decreases.
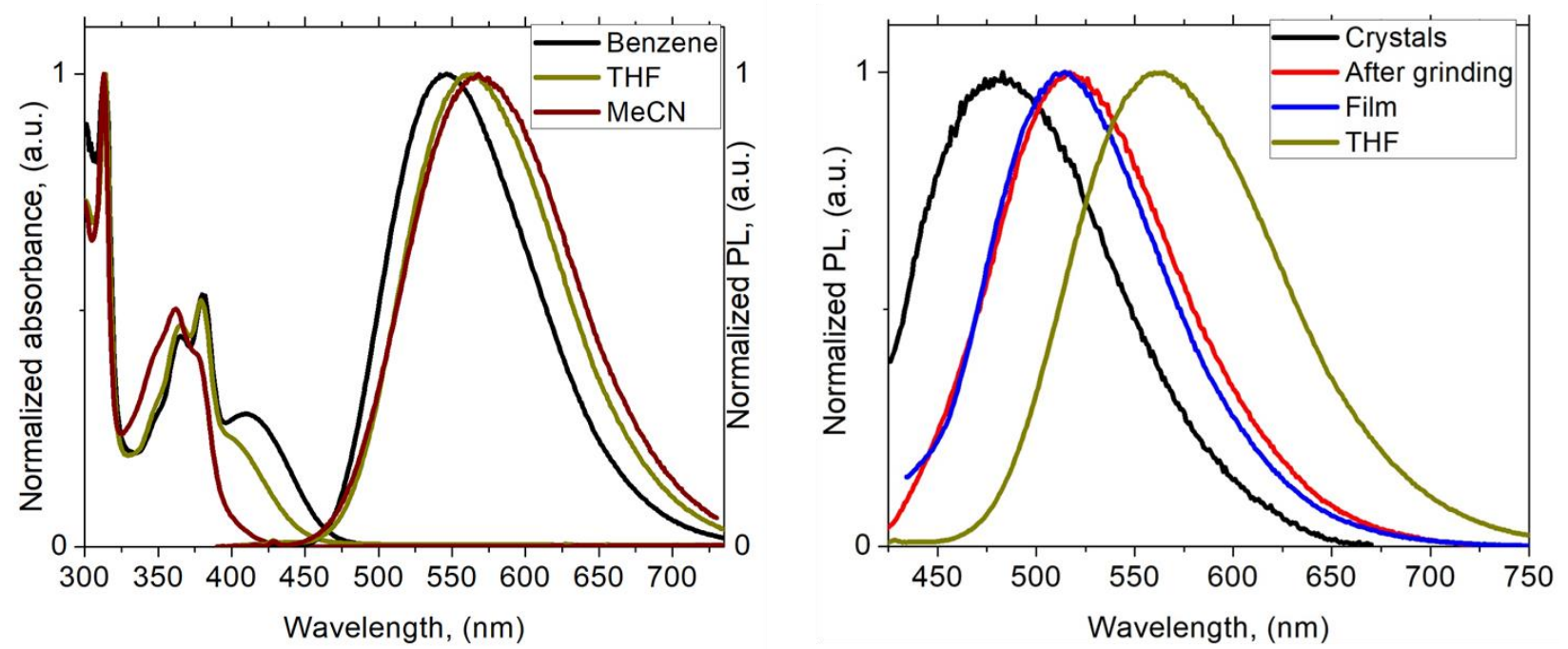

Figure 2. Left: UV-vis (normalized at $310 \mathrm{~nm})$ and solution PL spectra $\left(\lambda_{\mathrm{exc}}=380 \mathrm{~nm}\right)$ for 2. Right: emission spectra $\left(\lambda_{\mathrm{exc}}=380 \mathrm{~nm}\right)$ for $\mathbf{2}$ in various environments. Films were drop-cast from THF solutions and annealed at $80{ }^{\circ} \mathrm{C}$ for $5 \mathrm{~min}$.

The steady-state PL properties, of $\mathbf{1}$ and $\mathbf{2}$ depend on the environment (Tables 2, SI Table S2). At $298 \mathrm{~K}$ both compounds exhibit broad and featureless green to yellow emissions, characteristic of CT-type excitations and consistent with calculations. Intact crystalline samples of $\mathbf{1}$ and $\mathbf{2}$ show low quantum yields (up to 17\%) which are significantly improved by grinding (to $33 \%$ ) or by drop-casting as thin films (to $45 \%$ ). Processing samples in this way leads to a red shift by $30 \mathrm{~nm}$ compared to the as-crystallized sample (Figure 2; SI, Figures S9, S10), indicating that in the amorphous state lower-energy conformations are being accessed. 
The emission peaks of $\mathbf{1}$ and $\mathbf{2}$ in a polymer matrix red-shift less than in neat solid films. The largest shift, by up to $85 \mathrm{~nm}(380 \mathrm{meV})$ compared to as-crystallized samples, occurs in solution. Solvent polarity induces a much smaller shift (by $20 \mathrm{~nm}, 85 \mathrm{meV}$ ), which suggests that geometric relaxation in the excited state is more important than stabilization by solvent dipoles. The contrast between excitation from the ground state versus relaxation from the excited state (350 meV vs. $85 \mathrm{meV}$ shift with polarity) is in qualitative agreement with calculations indicating a reduced electric dipole moment in the excited state $\left(11.9 \mathrm{D}\right.$ in the ground state vs. $-4.9 \mathrm{D}$ in $\mathrm{S}_{1}$ geometry for 1). ${ }^{[17,18]}$ By contrast, organic TADF materials often show red-shifts of $100 \mathrm{~nm}$ or more with increasing polarity of solvent or polymer matrix. ${ }^{[17]}$ PL quantum yields in degassed solutions drop from $74 \%(55 \%)$ to $19 \%(8 \%)$ for 1 (2) as solvent polarity increases. In deoxygenated solutions 1 and $\mathbf{2}$ exhibit monoexponential decays with lifetimes of 200-500 ns (Table 2 and SI, Figure S13), implying radiative rate constants exceeding $10^{6} \mathrm{~s}^{-1}$ at $300 \mathrm{~K}$. The emissions are strongly quenched by $\mathrm{O}_{2}$, indicating the involvement of triplet states in the decay mechanism.

In solid films at $50 \mathrm{~K}$, steady-state emission spectra of $\mathbf{1}$ and $\mathbf{2}$ blue-shift and develop additional structure (Figure $3 \mathrm{a}$ and SI, Figure S11). To understand this behavior, we turn to transient PL over a range of temperatures, measured using an electrically-gated ICCD camera. Figure $3 b$ presents time-resolved PL decays for amorphous films of complex 2 (for decays of $\mathbf{1}$ see Figure S14). PL transients are characterized by non-exponential kinetics over three distinct time regimes - nanosecond (I), microsecond (II) and 100s of microseconds (III), with the latter significant only at low temperatures. The early-time decay $\left(\tau_{\mathrm{I}}=4 \mathrm{~ns}\right)$ exhibits no significant $T$ dependence, but these lifetimes are likely limited by the ICCD instrument response $(\sim 3 \mathrm{~ns})$. We assign (I) to prompt fluorescence, with an estimated energy in excess of $2.92 \mathrm{eV}$. Spectral deconvolution indicates that its emission spectrum is blue-shifted compared to that at later times (Figure 3a). Luminescence in regime (II) is unstructured and thermally activated, with an activation energy of $84 \mathrm{meV}$ for $2\left(108 \mathrm{meV}\right.$ for $\mathbf{1}$, Figure S12) and lifetimes ranging from $\tau_{\mathrm{II}}=$ $420 \mathrm{~ns}$ at $300 \mathrm{~K}$ to $20 \mu \mathrm{s}$ at $50 \mathrm{~K}$ (380 ns to $11 \mu \mathrm{s}$ for 1, Figure S14). This is consistent with a TADF-type emission process. We thus assign regime (II) to TADF from the reservoir of ${ }^{3} \mathrm{CT}$ states created following intersystem crossing from the photoexcited singlet. ${ }^{[19]}$ We attribute the nonexponential decay to emission from an ensemble of such CT states in different local configurations within the solid film, consistent with a gradual red-shift in emission during the decay. This regime 
accounts for $>90 \%$ of total emission at room temperature (note that the delayed fluorescence spectra at 50 and $298 \mathrm{~K}$ and the neat film spectrum are essentially superimposable, Figures 2 and 3a and SI, Figure S14). The time-averaged spectra closely match electroluminescence from OLED devices (vide infra). Peak emission energy in this regime blue-shifts at lower temperature (Figure 3c), with a greater shift for $\mathbf{1}$ than for $\mathbf{2}$. We interpret this as a reduced capacity for geometrical relaxation of the excited state, restricting both ${ }^{1} \mathrm{CT}$ and ${ }^{3} \mathrm{CT}$ manifolds to higher energy. Below $150 \mathrm{~K}$, a weak third component is distinguishable at long times $\left(\tau_{\mathrm{III}}>100 \mu \mathrm{s}\right)$. The associated emission spectra are highly structured, and we assign (III) to phosphorescence from a local excitation on the carbazole ${ }^{3} \mathrm{LE}$ state. The energy of the ${ }^{3} \mathrm{LE}$ state was estimated from the emission spectrum at $50 \mathrm{~K}$ obtained after a time delay of $250 \mu \mathrm{s}$ and found to be $2.92 \mathrm{eV}$ for $\mathbf{1}$ and $2.88 \mathrm{eV}$ for $\mathbf{2}$, and it is thus accessible to excitations at the high-energy edge of the CT manifold.

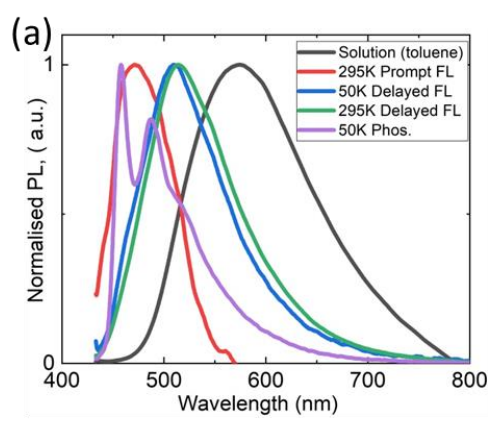

(d)

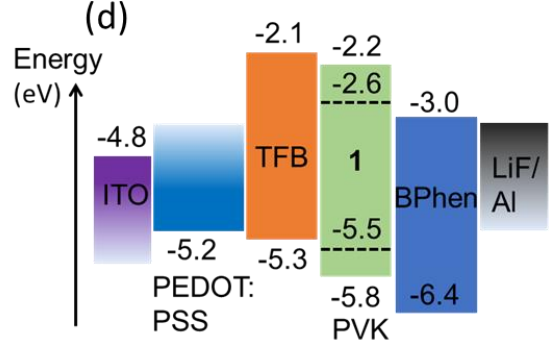

(g)

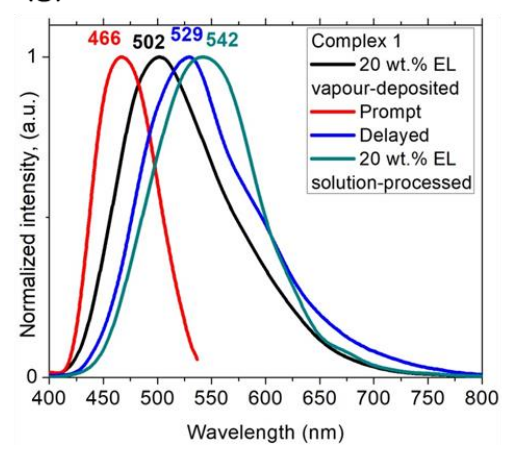

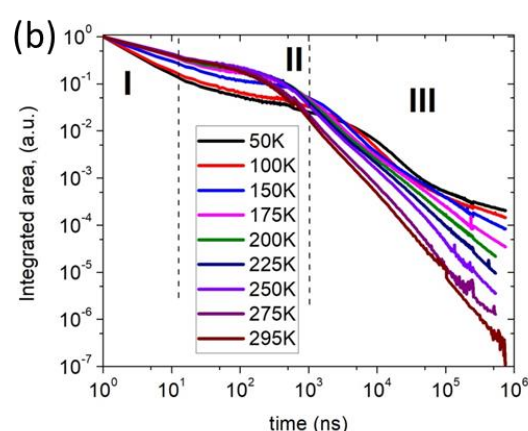

(e)

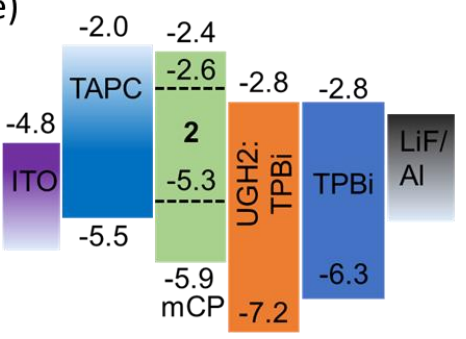

(h)

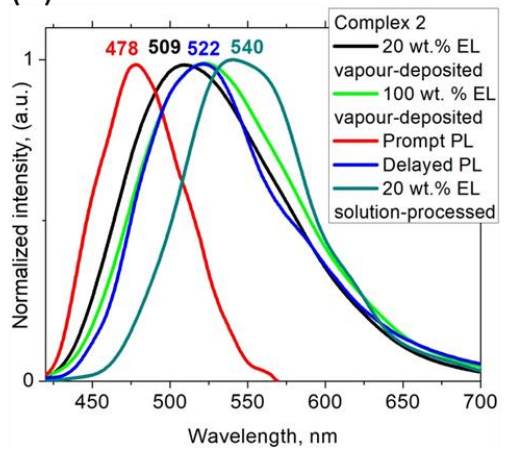

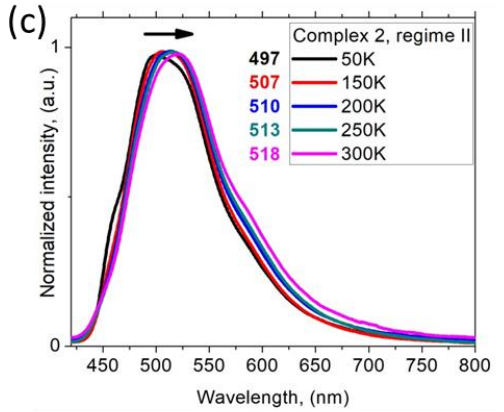

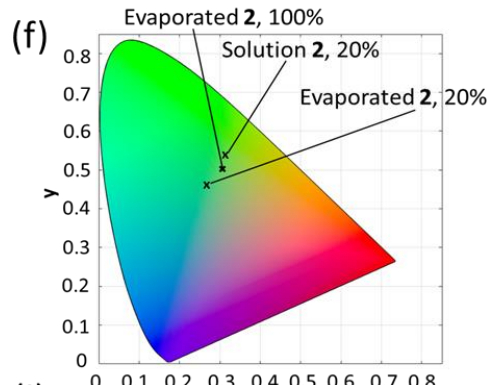

(i)

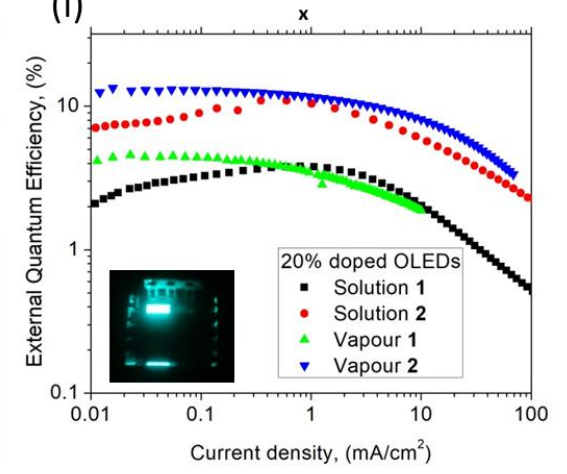


Figure 3. (a) Prompt (0-1 ns) fluorescence, delayed (100 ns) fluorescence and phosphorescence $(250 \mu \mathrm{s})$ spectra for 2 in film at $295 \mathrm{~K}$ and $50 \mathrm{~K}$, steady-state emission of $\mathbf{2}$ in toluene solution at 295K; (b) Time-resolved PL decay for films of 2 from 5 ns to $750 \mu$ s. (c) Temperature-dependent emission change for films of 2. (d) Vapour-deposited and (e) solution-processed OLED devices architectures; (f) Commission International de l'Éclairage (CIE) colour co-ordinates of thermally evaporated and solution-processed OLEDs with complex 2; (g) Electroluminescence (EL) and PL spectra for 1 and (h) for 2; (i) External quantum efficiencies vs. current density of champion OLEDs based on $\mathbf{1}$ and $\mathbf{2}$.

Table 2. Emission data of $\mathbf{1}$ and $\mathbf{2}$ in different environments.

\begin{tabular}{|c|c|c|c|c|c|c|}
\hline & \multicolumn{3}{|c|}{1} & \multicolumn{3}{|c|}{2} \\
\hline & Film & toluene & $\begin{array}{l}\mathrm{PVK}^{a} \\
\text { matrix }\end{array}$ & film & toluene & $\begin{array}{l}\mathrm{PVK}^{a} \\
\text { matrix }\end{array}$ \\
\hline$\lambda_{\mathrm{em}}(\mathrm{nm})$ & 496 & 521 & 500 & 514 & 546 & 509 \\
\hline$\tau$ & $\begin{array}{l}380 \mathrm{~ns} \\
(96 \%)\end{array}$ & $460 \mathrm{~ns}$ & $358 \mathrm{~ns}$ & $420 \mathrm{~ns}(96 \%)$ & $305 \mathrm{~ns}$ & $368 \mathrm{~ns}$ \\
\hline$\Phi(\%, 300 \mathrm{~K})$ & $19^{b}$ & $74^{c}$ & $36^{b}$ & $45^{b}$ & $54.7^{c}$ & $44^{b}$ \\
\hline$k_{\mathrm{r}}\left(10^{6} \mathrm{~s}^{-1}\right)$ & 0.5 & 1.6 & 1.0 & 1.1 & 1.8 & 1.2 \\
\hline$k_{\mathrm{nr}}\left(10^{6} \mathrm{~s}^{-1}\right)$ & 2.1 & 0.6 & 1.8 & 1.3 & 1.5 & 1.5 \\
\hline$E_{a}(\mathrm{meV})$ & 108 & - & - & 84 & - & - \\
\hline$\Delta E\left({ }^{1} C T-{ }^{3} L E\right)$ & \multicolumn{3}{|c|}{$-0.08 \mathrm{eV}^{a}$} & \multicolumn{3}{|c|}{$-0.06 \mathrm{eV}^{a}$} \\
\hline
\end{tabular}

${ }^{a}$ PVK = poly(9-vinylcarbazole); ${ }^{b}$ PLQY under air; ${ }^{c}$ PLQY under $\mathrm{N}_{2}$.

We conclude that at ambient temperature the PL of both compounds $\mathbf{1}$ and $\mathbf{2}$ is dominated by a TADF-type process with low activation energy and rapid (sub-microsecond) triplet harvesting, rendering them promising candidates for OLED applications. To this end, both thermally-evaporated and solution-processed fabrication routes were explored.

Thermal vacuum deposition is the industry-preferred fabrication process, offering greater control and reproducibility at the expense of greater complexity and higher demands on thermal stability. The vapor-deposited OLED devices with architecture shown in Figure 3e give green emissions, with EL peaks dependent on dopant concentration. OLEDs with $20 \mathrm{wt}-\%$ and $50 \mathrm{wt}-\%$ dopant in 1,3-bis(9-carbazolyl)benzene $(\mathrm{mCP})$ show EL peaks at $\lambda_{\mathrm{em}}=502(\mathbf{1}$, Figure $3 \mathrm{~g})$ and 509 
nm (2, Figure 3h). Host-free devices show EL peak broadening and a red-shift to $521 \mathrm{~nm}$, while the EL spectra closely match the microsecond-regime PL spectra. Figure S15 shows current density-voltage and luminance-voltage characteristics of evaporated devices with varying dopant concentrations. High external quantum efficiencies (EQEs) (for 2: $12.9 \%$ at $100 \mathrm{~cd} / \mathrm{m}^{2}$ and $10 \%$ at $1000 \mathrm{~cd} / \mathrm{m}^{2}$ ) are achieved, with good roll-off characteristics. The maximum EQE is higher at low current-densities, indicating good charge balance, which is supported by the low turn-on voltage (Table 3).

Solution processing employed a multilayer OLED structure with all four organic layers being processed using orthogonal solvents, resulting in peak EQEs of 3.8\% and $11.0 \%$ for $\mathbf{1}$ and 2, respectively (Figures 3d and S15). Compared to vacuum-processed OLEDs the EL spectra are red-shifted, ${ }^{[20]}$ and solution-processed devices made from 2 showed slightly increased roll off $\left(11.0 \%\right.$ at $200 \mathrm{~cd} / \mathrm{m}^{2}$ and $8 \%$ at $1000 \mathrm{~cd} / \mathrm{m}^{2}$ ), higher turn on voltage and reduced EQE at low current densities due to a slight imbalance in charge injection. This is to be expected given the difficulty in precisely controlling injection layer thickness in multilayer solution-processed architectures.

Table 3. Performance data of solution and evaporated OLEDs

\begin{tabular}{cccccc}
\hline $\begin{array}{c}\text { Dopant } \\
{[\text { wt.\%]/ }} \\
\text { Method }\end{array}$ & $\begin{array}{c}\text { VON } \\
{[\mathrm{V}]}\end{array}$ & $\begin{array}{c}\eta_{\mathrm{EQE}, \mathrm{EL}}[\%] \\
\text { (Max.) }\end{array}$ & $\begin{array}{c}\eta_{\mathrm{EQE}, \mathrm{EL}}[\%] \\
\left(100 \mathrm{cdm}^{-2}\right)\end{array}$ & $\begin{array}{c}\eta_{\mathrm{EQE}, \mathrm{EL}}[\%] \\
\left(1000 \mathrm{cdm}^{-2}\right)\end{array}$ & $\begin{array}{c}\mathrm{CIE}^{a} \\
(\mathrm{x}, \mathrm{y})\end{array}$ \\
\hline $\begin{array}{c}\mathbf{1}[20] \\
\text { Evaporated }\end{array}$ & 4.3 & 4.3 & 2.7 & $\mathrm{~N} / \mathrm{A}$ & $(0.26,0.42)$ \\
\hline $\begin{array}{c}\mathbf{1}[50] \\
\text { Evaporated }\end{array}$ & 4.0 & 4.6 & 3.3 & $\mathrm{~N} / \mathrm{A}$ & $(0.25,0.42)$ \\
\hline $\begin{array}{c}\mathbf{2}[20] \\
\text { Evaporated }\end{array}$ & 4.3 & 13.7 & 12.9 & 10.0 & $(0.28,0.46)$ \\
\hline $\begin{array}{c}\mathbf{2}[100] \\
\text { Evaporated }\end{array}$ & 4.0 & 8.2 & 7.4 & 5.2 & $(0.31,0.50)$ \\
\hline $\begin{array}{c}\mathbf{1}[20] \\
\text { Solution }\end{array}$ & 4.8 & 3.8 & 3.8 & 1.2 & $(0.35,0.52)$ \\
\hline $\begin{array}{c}\mathbf{2}[20] \\
\text { Solution }\end{array}$ & 5.0 & 11.0 & 10.6 & 8.2 & $(0.36,0.56)$ \\
\hline
\end{tabular}

${ }^{a}$ Commission Internationale de l'Éclairage (CIE) color co-ordinates

To conclude, (CAAC)silver amides are photo- and thermally stable TADF emitters which show the largest donor...acceptor separation in the coinage metal triad and give high radiative rates for triplet harvesting. Calculations indicate that the $S_{1}$ excited state geometry experiences 
significant deviation from linearity, while the ligand-plane twist angle is the lowest in the isostructural coinage metal series. Efficient vapour- and solution-processed OLEDs have been fabricated with EQEs up to $12.9 \%$ at practical brightness, and a maximum luminance of 21,000 $\mathrm{cd} / \mathrm{m}^{2}$. The results show that lighter, cheaper and more abundant $2^{\text {nd }}$ row elements may provide an as-yet little tapped resource for emitter materials.

\section{Acknowledgements}

This work was supported by the European Research Council, the Royal Society. M. B. is an ERC Advanced Investigator Award holder (grant no. 338944-GOCAT). D.C. acknowledges support from the Royal Society (grant nos. UF130278 and RG140472). The computations were made possible by use of the Finnish Grid Infrastructure resources (urn:nbn:fi:research-infras2016072533). We thank S. Polonius and A. Reponen for assistance with initial data.

\section{Supporting Information}

For Supporting Information and crystallographic data in CIF or other electronic format see DOI: 10.1039/XXXXXX. CCDC number 1832143 for $\mathbf{1}$ and 1832142 for $\mathbf{2}$ contains the supplementary crystallographic data for this paper. These data can be obtained free of charge from the Cambridge Crystallographic Data Centre via www.ccdc.cam.ac.uk/data_request/cif.

\section{References}

[1] a) C. Bizzarri, F. Hundemer, J. Busch, S. Bräse, Polyhedron, 2018, 140, 51-66; b) H. Yersin, R. Czerwieniec, M. Z. Shafikov, A. F. Suleymanova, Chem. Phys. Chem., 2017, 18, 3508-3535; c) Y. Zhang, S. R. Forrest, Phys. Rev. Lett., 2012, 108, 267404; d) H. Yersin, Highly Efficient OLEDs with Phosphorescent Materials, Wiley-VCH, Weinheim, 2008; ISBN 978-3527-40594-7; e) M. A. Baldo, D. F. O'Brien, Y. You, A. Shoustikov, S. Sibley, M. E. Thompson, S. R. Forrest, Nature, 1998, 395, 151-154.

[2] A. S. Romanov, D. Di, L. Yang, J. Fernandez-Cestau, C. R. Becker, C. E. James, B. Zhu, M. Linnolahti, D. Credgington, M. Bochmann, Chem. Commun. 2016, 52, 6379-6382 and 2018, 54,3672 .

[3] A. S. Romanov, M. Bochmann, J. Organomet. Chem. 2017, 847, 114-120. 
[4] A. S. Romanov, C. R. Becker, C. E. James, D. Di, D. Credgington, M. Linnolahti, M. Bochmann, Chem. Eur. J., 2017, 23, 4625-4637. b) M. Gernert, U. Meller, M. Haehnel, J. Pflaum, A. Steffen, Chem. Eur. J. 2017, 23, 2206-2216; c) R. Hamze, R. Jazzar, M.

Soleilhavoup, P. I. Djurovich, G. Bertrand, M. E. Thompson, Chem. Commun. 2017, 53, 90089011.

[5] D. Di, A. S. Romanov, L. Yang, J. M. Richter, J. P. H. Rivett, S. Jones, T. H. Thomas, M. A. Jalebi, R. H. Friend, M. Linnolahti, M. Bochmann, D. Credgington, Science, 2017, 356, 159163.

[6] P. J. Conaghan, S. M. Menke, A. S. Romanov, S. T. E. Jones, A. J. Pearson, E. W. Evans, M. Bochmann, N. C. Greenham, D. Credgington, Adv. Mater., 2018, 30, 1802285.

[7] OLEDs based on Ag-Pt clusters have been reported: H.-X. Shu, J.-Y. Wang, Q.-C. Zhang, Z.-N. Chen, Inorg. Chem. 2017, 56, 9461-9473; b) Y.-P. Li, X.-X. Fan, Y. Wu, X.-C. Zeng, J.-Y. Wang, Q.-H. Wei, Z.-N. Chen, J. Mater. Chem. C, 2017, 5, 3072-3078.

[8] $\mathrm{Ru}$ and Pd based OLEDs have been reported, with EQEs <1\%: (a) J. Yang, K. C. Gordon, Chem. Phys. Lett. 2003, 372, 577-582. (b) H. Xia, C. Zhang, X. Liu, S. Qiu, P. Lu, F. Shen, J. Zhang, Y. Ma, J. Phys. Chem. B 2004, 108, 3185-3190. (c) A. F. Henwood, M. Lesieur, A. K. Bansal, V. Lemaur, D. Beljonne, D. G. Thompson, D. Graham, A. M. Z. Slawin, I. D. W. Samuel, C. S. J. Cazin, E. Zysman-Colman, Chem. Sci. 2015, 6, 3248-3261

[9] H-L. Su, L. M. Perez, S-J. Lee, J. H. Reibenspies, H. S. Bazzi, D. E. Bergbreiter, Organometallics, 2012, 31, 4063-4071.

[10] C.M. Cardona, W. Li, A.E. Kaifer, D. Stockdale, G.C. Bazan, Adv. Mater., 2011, 23, 2367-2371.

[11] F. Furche, D. Rappoport, Density functional methods for excited states: equilibrium structure and electronic spectra. In: Computational Photochemistry; M. Olivuccim, Ed.; Elsevier: Amsterdam, 2005; pp. 93-128.

[12] H.S. Yu, X. He, S.L. Li, D.G. Truhlar, Chem. Sci. 2016, 7, 5032-5051.

[13] F., Weigend, M. Häser, H. Patzelt, R. Ahlrichs, Chem. Phys. Lett. 1998, 294, 143-152.

[14] F. Weigend, R. Ahlrichs, Phys. Chem. Chem. Phys. 2005, 7, 3297-3305.

[15] D. Andrae, U. Haeussermann, M. Dolg, H. Stoll, H. Preuss, Theor. Chim. Acta 1990, 77, $123-141$.

[16] A. Dreuw, M. Head-Gordon, Chem. Rev. 2005, 105, 4009-4037. 
[17] J. Föller, C.M. Marian, J. Phys. Chem. Lett., 2017, 8 (22), 5643-5647.

[18] a) F. B. Dias, T. J. Penfold, A. P. Monkman, Methods Appl. Fluoresc. 2017, 5, 012001;

b) M. K. Etherington, J. Gibson, H. F. Higginbotham, T. J. Penfold, A. P. Monkman, Nat. Commun. 2016, 7, 13680; c) K. Suzuki, S. Kubo, K. Shizu, T. Fukushima, A. Wakamiya, Y. Murata, C. Adachi, H. Kaji, Angew.Chem. Int. Ed. 2015, 54, 15231-15235.

[19] T. Hosokai, H. Matsuzaki, H. Nakanotani, K. Tokumaru, T. Tsutsui, A. Furube, K. Nasu, H. Nomura, M. Yahiro, C. Adachi, Sci. Adv., 2017, 3, e1603282.

[20] Similar correlations were reported for vapour-deposited OLED devices with $\left({ }^{\mathrm{Ad}} \mathrm{L}\right) \mathrm{Au}$ (carbazolate), ref. [6]. 